\title{
Invariant allometric scaling of nitrogen and phosphorus in leaves, stems, and fine roots of woody plants along an altitudinal gradient
}

\author{
Ning Zhao ${ }^{1,2} \cdot$ Guirui $\mathrm{Yu}^{2} \cdot$ Nianpeng $\mathrm{He}^{2} \cdot$ Fucai Xia $^{3}$ - Qiufeng Wang ${ }^{2} \cdot$ \\ Ruili Wang ${ }^{2} \cdot{\text { Zhiwei } \mathrm{Xu}^{2} \cdot \text { Yanlong Jia }}^{2}$
}

Received: 2 November 2014 / Accepted: 18 January 2016 / Published online: 4 March 2016

(C) The Botanical Society of Japan and Springer Japan 2016

\begin{abstract}
Nitrogen (N) to phosphorus (P) allocation in plant organs is of particular interest, as both elements are important to regulate plant growth. We analyzed the scaling relationship of $\mathrm{N}$ and $\mathrm{P}$ in leaves, stems and fine roots of 224 plant species along an altitudinal transect (500-2,300 m) on the northern slope of Changbai Mountain, China. We tested whether the scaling relationships of $\mathrm{N}$ and $\mathrm{P}$ were conserved in response to environmental variations. We found that the $\mathrm{N}$ and $\mathrm{P}$ concentrations of the leaves, stems and fine roots decreased, whereas the N:P ratios increased with increasing altitude. Allometric scaling relationships of $\mathrm{N}$ and $\mathrm{P}$ were found in the leaves, stems and fine roots, with allometric exponents of $0.78,0.71$ and 0.87 , respectively. An invariant allometric scaling of $\mathrm{N}$ and $\mathrm{P}$ in the leaves, stems and fine roots was detected for woody plants along the altitudinal gradient. These results may advance our understanding of plant responses to climate change, and provide a basis for practical implication of various ecological models.
\end{abstract}

Guirui Yu

yugr@igsnrr.ac.cn

$\bowtie$ Nianpeng He

henp@igsnrr.ac.cn

1 Key Laboratory of Remote Sensing of Gansu Province, Heihe Remote Sensing Experimental Research Station, Cold and Arid Regions Environmental and Engineering Research Institute, Chinese Academy of Sciences, Lanzhou 730000, China

2 Synthesis Research Center of Chinese Ecosystem Research Network, Key Laboratory of Ecosystem Network Observation and Modeling, Institute of Geographic Sciences and Natural Resources Research, Chinese Academy of Sciences, Beijing 100101, China

3 Foresty College of Beihua University, Jilin 132013, China
Keywords Allometry · Elevation - Life history strategy · Nutrient allocation $\cdot$ Plant growth form $\cdot$ Stoichiometry

\section{Introduction}

Nutrient allocation is the fundamental part of the resource capture strategies of plants, which impacts on the material and energy cycles of terrestrial ecosystems (Ågren 2004; Elser et al. 2007; Heberling and Fridley 2012). Leaves and roots are major plant organs that implement carbon assimilation and nutrient uptake, respectively, while stems are important intermediaries used to link the leaves and roots. The nutrient concentrations of leaves, stems and roots are related to organ function, organ growth and turnover rates, and plant growth form (Kerkhoff et al. 2006; Minden and Kleyer 2014; Westoby et al. 2002; Yang et al. 2014). Understanding the partitioning of nutrients among plant organs and how this mechanism responds to environmental gradients is, therefore, crucial for predicting how nutrient fluxes and ecosystem functions will respond to the change of temperature and precipitation.

The nitrogen $(\mathrm{N})$ to phosphorus $(\mathrm{P})$ relationship in plant organs is of particular interest, as $\mathrm{N}$ and $\mathrm{P}$ are important elements that regulate plant growth, with both elements being critical in regulating ecosystem functions and dynamics (Chapin et al. 1986; Elser et al. 2007; Güsewell 2004; Vitousek et al. 2010). Scaling relationships are widely used to explain the observed patterns of various plant traits, including metabolic and physical traits (Brown et al. 2004; Price et al. 2012; Wright et al. 2004; Xiang et al. 2013; Yang et al. 2014). These relationships may be defined by 'characteristic slopes and intercepts on a log-log scale, based on the general scaling 
relationship $Y=b X^{a}$ (Kerkhoff et al. 2005; Reich et al. 2010). It has been found that the scaling of $\mathrm{N}$ concentration as a function of $\mathrm{P}$ concentration in different plant organs can be well described by allometric relationship, in which the common log-log slope was significantly smaller than 1 (Ågren 2008; Elser et al. 2010; Kerkhoff et al. 2006; Reich et al. 2010; Wright et al. 2004). Many studies have demonstrated that the allometric relationship between leaf $\mathrm{N}\left(\mathrm{N}_{\mathrm{L}}\right)$ and leaf $\mathrm{P}\left(\mathrm{P}_{\mathrm{L}}\right)$ are similar at various scales, spanning from the local to global scale, with ranges of 0.67 to 0.72 for slopes $(a)$ of the scaling functions (Garten 1976; Han et al. 2005; Kerkhoff et al. 2006; Reich et al. 2010; Wright et al. 2004). Furthermore, allometric relationship have also been detected in the roots and stems, for which the slopes $(a)$ of the scaling functions are 0.76 (Yuan et al. 2011) and 0.70 (Kerkhoff et al. 2006), respectively.

The acquisition of $\mathrm{N}$ and $\mathrm{P}$ in plants is influenced by climate (Reich and Oleksyn 2004), soil conditions (Chen et al. 2011; Dijkstra et al. 2012; Stock and Verboom 2012), phylogeny (Hao et al. 2014; Stock and Verboom 2012) and different physiological growth strategies among species (Kerkhoff et al. 2006). Previous studies have demonstrated that $\mathrm{N}, \mathrm{P}$ and the $\mathrm{N}: \mathrm{P}$ of leaves noticeably change with temperature, precipitation and soil condition along latitudinal gradients (Han et al. 2005; Reich and Oleksyn 2004). In contrast, Reich et al. (2010) reported a consistent allometric scaling pattern of $N_{L}$ to $P_{L}$ with a uniform $2 / 3 \log -\log$ slope across dramatic biogeographical gradients. It suggested that the allometric relationship of $\mathrm{N}_{\mathrm{L}}$ and $\mathrm{P}_{\mathrm{L}}$ is conserved at some extent, regardless of biotic and environmental variation (Reich et al. 2010). We have evidence from plant leaves, however, until recently we still know little about such relationship in non-leaf organs of plants. Here, we conducted an experiment along an altitudinal transect to test whether the scaling relationship of $\mathrm{N}$ and $\mathrm{P}$ in major plant organs are conserved in response to environmental variations.

The substantial variation in microhabitat structure along altitudinal gradient provides an excellent natural laboratory to investigate the response of $\mathrm{N}$ and $\mathrm{P}$ relationship in plant organs to environmental changes. Changbai Mountain in China has clear vertical vegetation zonation that ranges from mixed coniferous broadleaved forest at low altitude to alpine tundra above $2100 \mathrm{~m}$ (Shao et al. 1996; Zhang et al. 2011). In this study, we investigated the $\mathrm{N}$ and $\mathrm{P}$ concentrations of the leaves $\left(\mathrm{N}_{\mathrm{L}}, \mathrm{P}_{\mathrm{L}}\right)$, stems $\left(\mathrm{N}_{\mathrm{S}}, \mathrm{P}_{\mathrm{S}}\right)$ and fine roots $\left(\mathrm{N}_{\mathrm{R}}\right.$, $\mathrm{P}_{\mathrm{R}}$ ) along an altitudinal transect $(500-2,300 \mathrm{~m})$ on the northern slope of Changbai Mountain, China. The main objectives of this study were to investigate: (1) How do $\mathrm{N}, \mathrm{P}$ concentrations and $\mathrm{N}: \mathrm{P}$ in the leaves, stems and fine roots vary with environmental gradient; (2) whether the observed scaling relationship differ among different plant organs and plant growth forms; and (3) whether the scaling relationship vary with environmental gradient along the altitudinal transect?

\section{Materials and methods}

Site description-Changbai Mountain (N41 $23^{\prime}-42^{\circ} 36^{\prime}$, E126 $\left.55^{\prime}-129^{\circ} 00^{\prime}\right)$ is the highest mountain $(2744 \mathrm{~m})$ on the eastern coast of Eurasia, and is located on the border of China and North Korea. With increasing altitude (500$2744 \mathrm{~m}$ ), the mean annual temperature (MAT) decreases from 3.5 to $-7.4{ }^{\circ} \mathrm{C}$ and mean annual precipitation (MAP) increases from 720 to $1400 \mathrm{~mm}$ (Zhu et al. 2010). As a national nature reserve, the natural ecosystems of Changbai Mountain are well conserved. The vertical distribution of vegetation includes mixed coniferous broadleaved forests at low altitudes $(500-1100 \mathrm{~m})$, spruce and fir conifer forests at middle altitudes $(1100-1800 \mathrm{~m})$, birch forests (1800-2100 m) and alpine tundra (above $2100 \mathrm{~m}$ ) at high altitudes. The environmental features and dominant species along the altitudinal transect were summarized in Table 1.

Experiment design and sampling-Within the transect along the northern slope of Changbai Mountain, three altitudinal zones were investigated, referred to here as low, middle, and high altitudinal zones. Six sites were sampled in total, with two of them in the mixed forest at low altitude, two in the conifer forest at middle altitude, and other two sites in the birch forest and alpine tundra at high altitude, respectively. Four experimental plots $(30 \times 40 \mathrm{~m})$ were set for each site and thus 24 plots were sampled in total. Leaves, stems and roots were collected from four plots as four independent replicates at each site.

In early August 2012, totally 2816 plant samples (1076 leaf samples, 752 stem samples and 988 root samples) were collected, which involving 224 species on the whole. The number of sample species at each site was detailed in Table 1. There were 269 site-species combinations, with 185 species occurring at more than one site. In field sampling, above ground and below ground organs were collected by two work teams separately, and thus the sample sizes were different among different organs. In this study, twigs of woody species and stems of herbaceous species were sampled to maximize the comparability of tissue nutrient content across plant 
Table 1 Summary of vegetation, environmental features and the number of sample species of six sites along the altitudinal transect on Changbai Mountain

\begin{tabular}{|c|c|c|c|c|c|c|}
\hline \multirow{3}{*}{$\begin{array}{l}\text { Altitude zone } \\
\text { Vegetation type } \\
\text { Site }\end{array}$} & \multicolumn{2}{|l|}{ Low } & \multicolumn{2}{|l|}{ Middle } & \multicolumn{2}{|l|}{ High } \\
\hline & \multicolumn{2}{|c|}{ Mixed coniferous broad-leaved forest } & \multicolumn{2}{|c|}{ Spruce and fir conifer forests } & \multirow{2}{*}{$\begin{array}{l}\text { Ermans birch forest } \\
\text { Site E }\end{array}$} & \multirow{2}{*}{$\begin{array}{l}\text { Alpine tundra } \\
\text { Site F }\end{array}$} \\
\hline & Site A & Site B & Site $\mathrm{C}$ & Site D & & \\
\hline Altitude (m) & 540 & 760 & 1300 & 1700 & 2000 & 2400 \\
\hline $\operatorname{MAT}\left({ }^{\circ} \mathrm{C}\right)$ & 2.9 & 2.6 & 0.3 & -2.3 & -3.3 & -4.8 \\
\hline MAP (mm) & 632 & 691 & 811 & 967 & 1038 & 1154 \\
\hline $\operatorname{STN}\left(\mathrm{mg} \mathrm{g}^{-1}\right)$ & 7.39 & 4.92 & 0.78 & 3.79 & 2.71 & 2.20 \\
\hline $\mathrm{STP}\left(\mathrm{mg} \mathrm{g}^{-1}\right)$ & 1.54 & 1.36 & 0.42 & 0.93 & 0.51 & 0.40 \\
\hline $\operatorname{SAN}\left(\mathrm{mg} \mathrm{kg}^{-1}\right)$ & 81.65 & 70.73 & 40.81 & 70.70 & 61.08 & 49.67 \\
\hline $\mathrm{SAP}\left(\mathrm{mg} \mathrm{kg}^{-1}\right)$ & 18.18 & 8.22 & 17.70 & 9.20 & 5.46 & 7.07 \\
\hline $\mathrm{pH}$ & 5.31 & 5.01 & 5.23 & 5.03 & 5.02 & 5.14 \\
\hline Species $_{L}$ & 67 & 86 & 36 & 38 & 22 & 20 \\
\hline Species $_{S}$ & 52 & 62 & 25 & 22 & 14 & 15 \\
\hline Species $_{R}$ & 61 & 75 & 40 & 44 & 15 & 12 \\
\hline $\begin{array}{l}\text { Dominant tree } \\
\text { species }\end{array}$ & Quercus mongolica & $\begin{array}{l}\text { Pinus koraiensis, } \\
\text { Acer tegmentosum }\end{array}$ & Abies nephrolepis & Picea jezoensis & Betula ermanii & $\begin{array}{c}\text { Dryas octopetala, } \\
\text { Rhododendron } \\
\text { chrysanthum }\end{array}$ \\
\hline
\end{tabular}

Species $_{L}$, Species ${ }_{S}$, and Species $_{R}$ represent number of leaf sample species, number of stem sample species, and number of root sample species, respectively

MAT mean annual temperature, MAP mean annual precipitation, STN soil total nitrogen, STP soil total phosphorus, $S A N$ soil available nitrogen, SAP soil available phosphorus

growth forms. For small herbaceous species, the whole plants of fully matured individuals were excavated and then transported to the laboratory for post processing. For woody species, sun-exposed and fully matured leaves were collected from individuals growing in situ, and then the branches with tips located at the outer surface of the plant's crown were chosen at random. To sample the roots of trees and shrubs, we first loosened the soil within a $2 \mathrm{~m}$ distance of the stem of the target tree on one side. Then, the root branches were followed to the tree stem to confirm the plant species. Subsequently, sections were cut from the main lateral woody roots.

Plant samples (including leaves, twigs or stems and roots) were cleaned carefully to remove soil particles and other materials. After cleaning, the leaves, stems (the most distal twigs) and fine roots (diameters $<2 \mathrm{~mm}$ ) were randomly selected and oven-dried at $60{ }^{\circ} \mathrm{C}$ in the laboratory, and then ground on a ball mill for chemical analysis.

In each plot, soil was randomly sampled from 30 to 50 points in the $0-10 \mathrm{~cm}$ and $10-30 \mathrm{~cm}$ layers, and the soil samples from the same depth were mixed. After being sieved (2-mm meshes), organic debris removed, one sub-sample was stored at $4{ }^{\circ} \mathrm{C}$ for available $\mathrm{N}$ analysis. The other sub-sample was air-dried and ground to fine powder using a ball mill (MM400, Retsch, Haan, Germany).

Chemical analysis-The $\mathrm{N}$ concentration of plant and soil total N (STN) were determined with an elemental analyzer (Vario MAX CN Elemental Analyzer, Elementar, Hanau, Germany). The P concentration of plant and soil total P (STP) was measured by the ammonium molybdate method using a continuous-flow analyzer (AutoAnalyzer3 Continuous-Flow Analyzer; Bran Luebbe, Hamburg, Germany) after $\mathrm{H}_{2} \mathrm{SO}_{4}-\mathrm{HClO}_{4}$ digestion for plant samples and $\mathrm{H}_{2} \mathrm{SO}_{4}-\mathrm{H}_{2} \mathrm{O}_{2}-\mathrm{HF}$ digestion for soil. Soil available $\mathrm{N}$ (SAN), which consist of $\mathrm{NH}_{4}{ }^{+}-\mathrm{N}$ and $\mathrm{NO}_{3}{ }^{-}-\mathrm{N}$, was extracted with $2 \mathrm{~mol} \mathrm{~L}^{-1} \mathrm{KCl}$ and measured using a continuous-flow analyser. Soil available P (SAP) was extracted from $5 \mathrm{~g}$ air-dried soil with $100 \mathrm{ml} 0.5 \mathrm{~mol} \mathrm{~L}^{-1}$ $\mathrm{NaHCO}_{3}$, and measured by the ammonium molybdate method.

Data analysis-The plant species were divided into three plant growth forms (PGFs): herbs, shrubs and trees. Differences in N, P concentrations and N:P ratios among different plant organs and PGFs were tested using analysis of variance (ANOVA) with Duncan's post hoc tests. Linear regression was employed to explore the pattern of $\mathrm{N}, \mathrm{P}$ concentrations and $\mathrm{N}: \mathrm{P}$ ratios in leaves, stems and fine roots along the altitudinal gradient. 
Table 2 Summary of the (partial) general linear models for the effects of plant growth form, climate and soil nutrient contents on stoichiometric traits of major plant organs

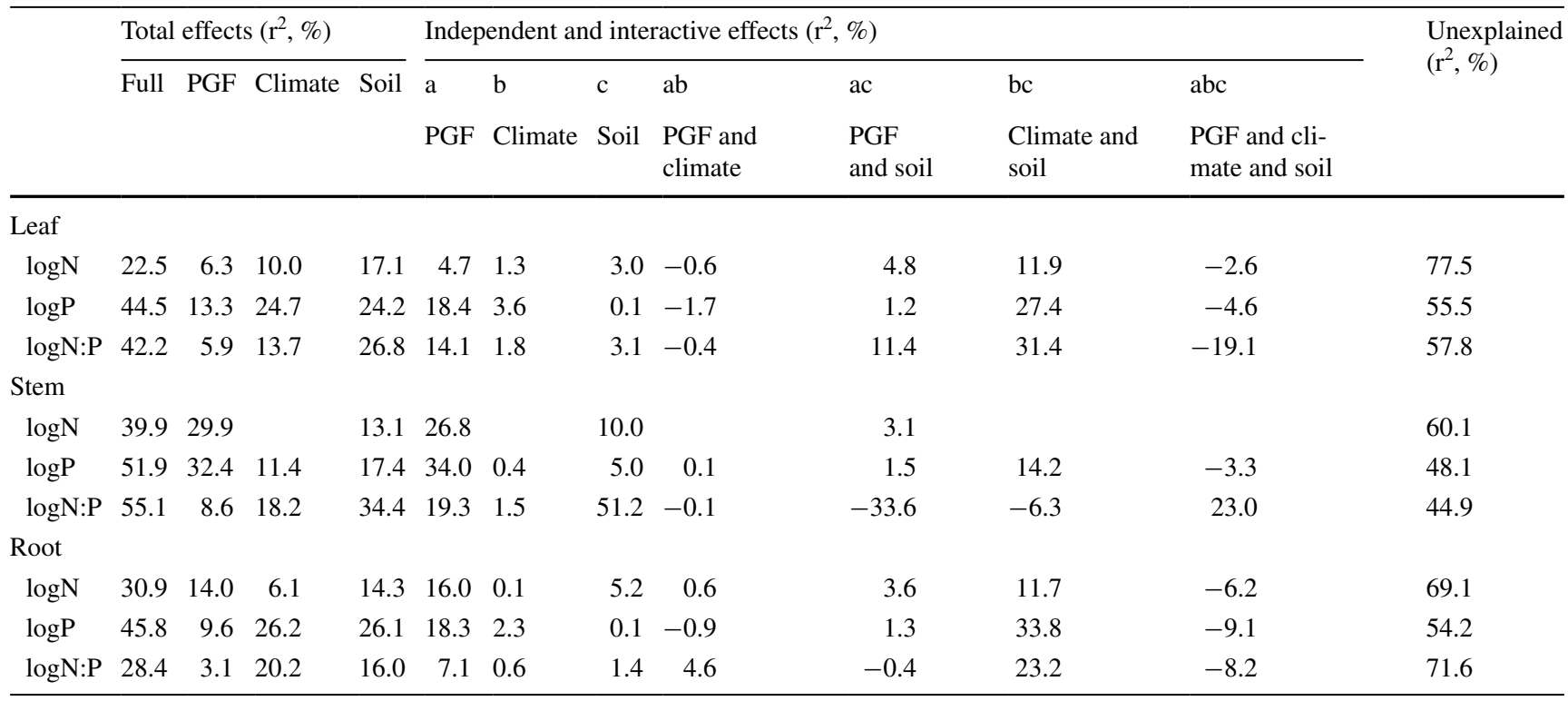

General linear model (GLM) was employed to test the effects of PGF, climate and soil on N, P concentrations and N:P ratios in leaves, stems and roots. Firstly, stepwise regressions were used to determine the climate (MAP and MAT) and soil variables (soil total nitrogen, STN; soil total phosphorus, STP; soil available nitrogen, SAN, and soil available phosphorus, SAP) which were included in each model of GLM. The variables that did not contribute significantly $(P<0.05)$ to the explained variation were excluded from the GLM (Tables 3, 4). Secondly, the partial General Liner Models (partial GLM) were used to separate the trait variations into different components: (1) a, b and c-the independent effects of PGF, climate and soil, respectively; (2) ab, ac, and bc-the interactive effects between PGF and climate, between PGF and soil, and between climate and soil, respectively; (3) abc-the interactive effect among PGF, climate and soil; (4) Unexplained variations (Table 2, for details of the statistics, see Han et al. 2011; Heikkinen et al. 2005; Zhao et al. 2014).

The scaling relationship of $\mathrm{N}$ and $\mathrm{P}$ in the plant organs is described by the equation:

$Y=b X^{a}$

or $\log (Y)=\log (b)+a \log (X)$

where $X$ and $Y$ are the $\mathrm{P}$ and $\mathrm{N}$ concentrations of a specific plant organ, respectively, $b$ is the y-intercept and $a$ is the slope of the scaling function, representing the allometric exponent.

To examine the scaling relationships of $\mathrm{N}$ and $\mathrm{P}$ in leaves, stems and fine roots, we used model II regression (also known as reduced major axis, RMA) on log-transformed values of $\mathrm{N}$ and $\mathrm{P}$ concentration (Sokal and Rohlf 1981). Parameter estimation of the allometric equations was implemented by using the "lmodel2" function in the "Imodel2" package of R (Legendre and Legendre 1998). To test for significant differences in stoichiometric scaling among herbs, shrubs and trees, we compared regression slopes within each organ among the three PGFs in a pairwise manner, using a likelihood ratio test (the "sma" function in the "smatr" package of $\mathrm{R})$.

We explored the response of the stoichiometric scaling relationship of the leaves, stems, and roots with the environmental gradient in the following steps. First, we used model II regression to estimate the parameters of allometric equations for each PGF at different altitude zones. Second, pairwise comparisons of the regression slopes between different altitude zones were implemented by using the likelihood ratio test. All statistical analyses were performed using R 3.1.0 (R Core Team, 2014).

\section{Results}

\section{$N, P$ and $N: P$ in leaves, stems and roots}

The concentrations of $\mathrm{N}, \mathrm{P}$ and $\mathrm{N}: \mathrm{P}$ ratios declined in the order of leaves, fine roots and stems (Fig. 1), while the variation of $\mathrm{N}, \mathrm{P}$ concentrations increased in the order of leaves, fine roots and stems $(\mathrm{CV}=25.4 \%$ and $32.3 \%$ for $\mathrm{N}_{\mathrm{L}}$ and $\mathrm{P}_{\mathrm{L}} ; \mathrm{CV}=37.1 \%$ and $45.7 \%$ for $\mathrm{N}_{\mathrm{R}}$ and $\mathrm{P}_{\mathrm{R}} ; \mathrm{CV}=40.5 \%$ and $53.8 \%$ for $\mathrm{N}_{\mathrm{S}}$ and $\mathrm{P}_{\mathrm{S}}$ ). 

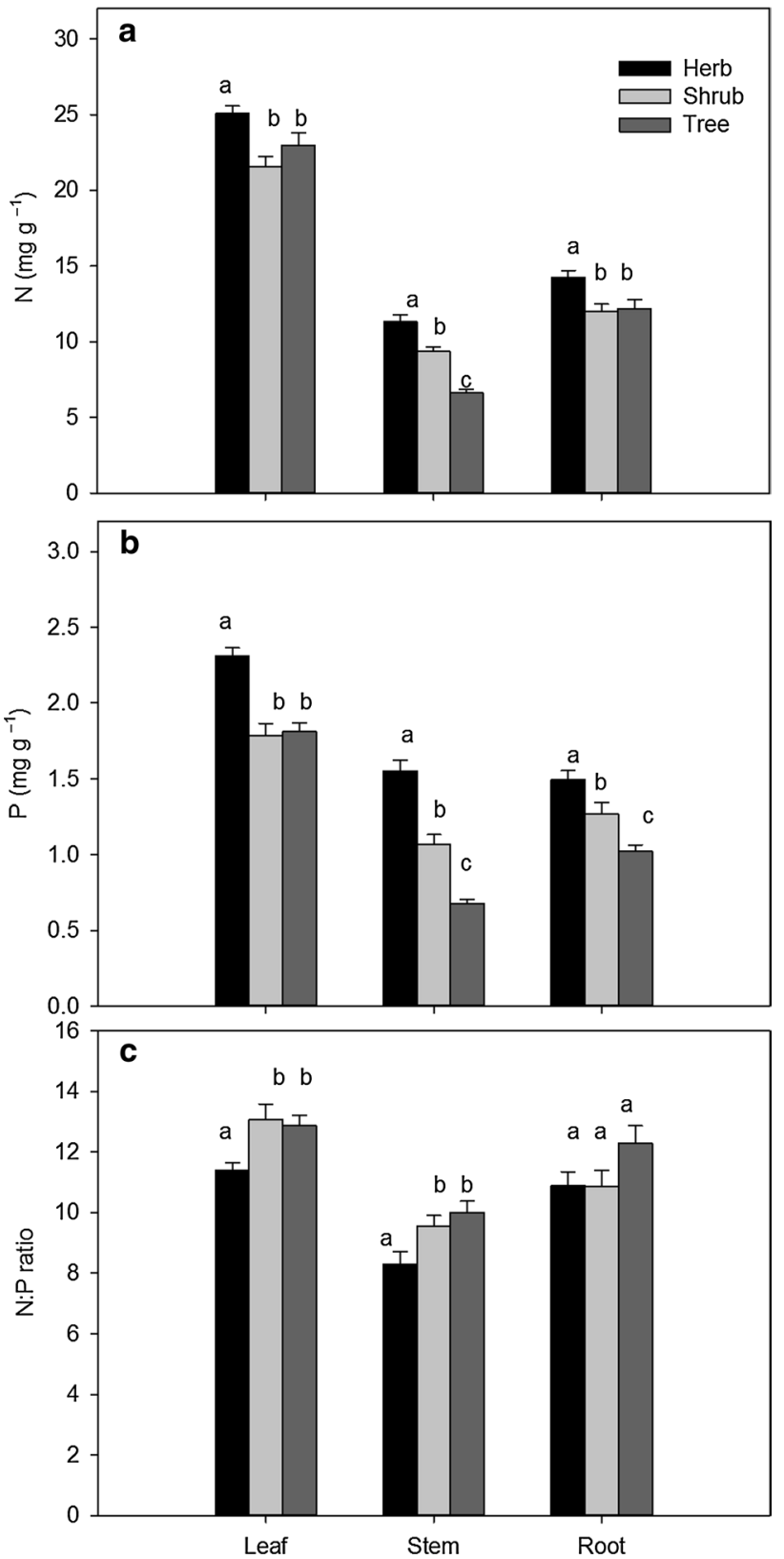

Fig. 1 Changes in N, P concentrations and N:P ratio in leaves, stems and fine roots of herbs, shrubs and trees. Different letters ( $a, b$ and $c$ ) indicate significant differences at 0.05 level

The average $\mathrm{N}$ and $\mathrm{P}$ concentration and $\mathrm{N}: \mathrm{P}$ ratio was $23.8 \pm 6.1,2.1 \pm 0.7$ and $12.1 \pm 3.3$ for leaves, $9.5 \pm 3.8$, $1.2 \pm 0.6$ and $9.1 \pm 3.2 \mathrm{mg} \mathrm{g}^{-1}$ for stems, and $13.1 \pm 4.8$, $1.3 \pm 0.6$ and $11.2 \pm 4.7 \mathrm{mg} \mathrm{g}^{-1}$ for fine roots, respectively. $\mathrm{N}_{\mathrm{L}}$ and $\mathrm{P}_{\mathrm{L}}$ varied four to seven fold, while $\mathrm{N}_{\mathrm{R}}$ and $P_{R}$ varied 11 to 13 fold across all species.

The N, P concentrations and N:P ratios differed significantly among different PGFs $(P<0.05)$. The $\mathrm{N}$ and $\mathrm{P}$ concentrations of all organs were the highest in herbs, followed
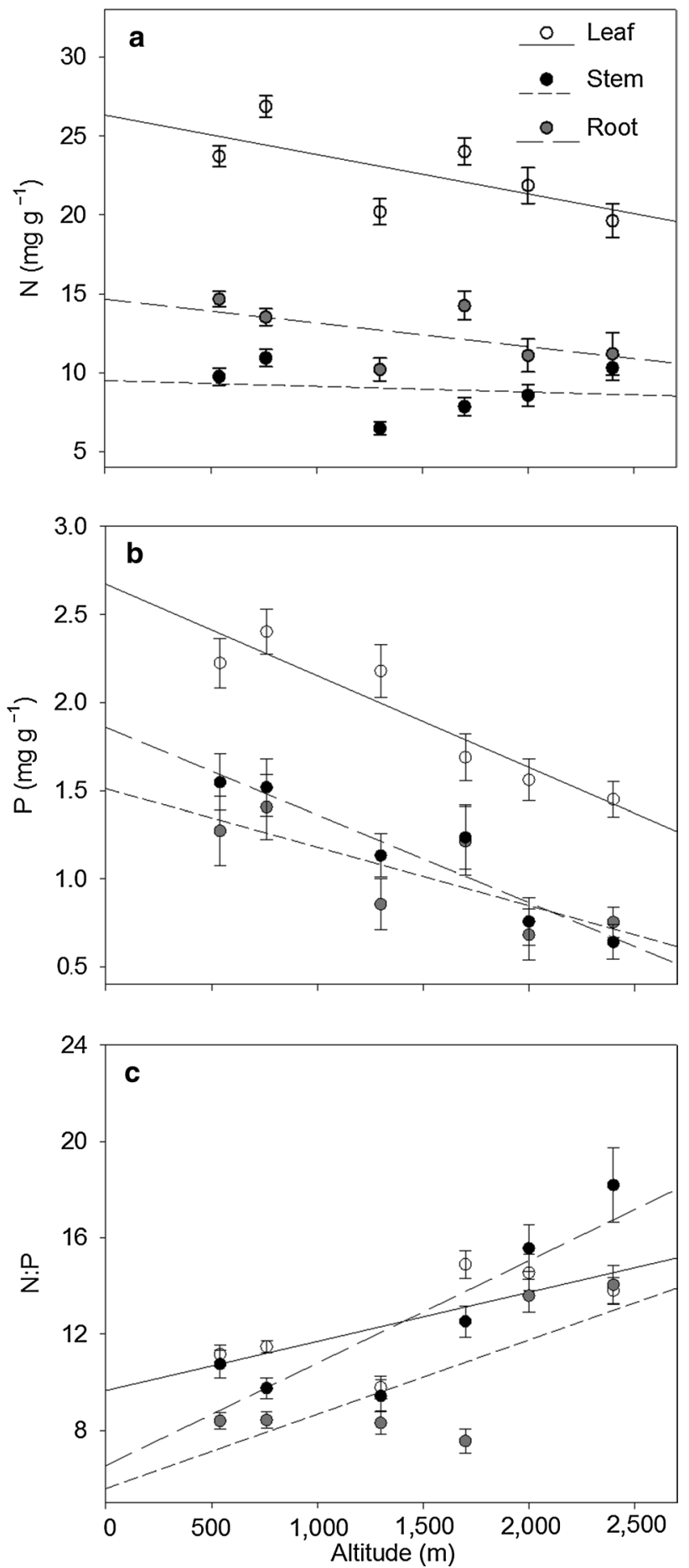

Fig. 2 N, P concentrations and N:P ratio of leaves, stems and fine roots in relation to altitude. Points and error bars show the means and standard errors for each vegetation type, respectively

by shrubs and trees (Fig. 1a, b). In contrast, herbs had lower $\mathrm{N}: \mathrm{P}$ within leaves and stems compared to the other two PGFs, while N:P ratio within fine roots did not show significant difference (Fig. 1c). 


\section{Patterns of $N, P$ concentrations and N:P ratio along the environmental gradient}

For all species pooled together, the $\mathrm{N}$ and $\mathrm{P}$ concentrations and N:P of leaves, stems and fine roots were significantly related to altitude (Fig. 2). The $\mathrm{N}$ concentrations in all the three organs decreased with the increases of altitude $\left(P<0.001, \mathrm{r}^{2}=0.06 ; P=0.031, \mathrm{r}^{2}=0.03\right.$ and $P=0.005, \mathrm{r}^{2}=0.03$, for leaves, stems and fine roots, respectively; Fig. 2a). Meanwhile, $P$ concentrations in all the three organs also showed a decline tendency (all $P<0.001, \mathrm{r}^{2}=0.24,0.12$ and 0.24 , for leaves, stems and fine roots, respectively; Fig. 2b). In comparison, the N:P ratios represented the opposite trend for all plant organs, increasing along elevation (all $P<0.001, \mathrm{r}^{2}=0.14,0.13$ and 0.11 , for leaves, stems and fine roots, respectively; Fig. 2c).

Plant growth form, climate and soil jointly influenced $\mathrm{N}$, $\mathrm{P}$ concentrations and $\mathrm{N}: \mathrm{P}$ ratios of major plant organs, with $22.5 \%-55.1 \%$ of total variations to be explained (Table 2). Environmental factors had a stronger effect on N, P concentrations and $\mathrm{N}: \mathrm{P}$ ratios in leaves and roots, while plant growth form had a stronger effect on $\mathrm{N}$ and $\mathrm{P}$ concentrations in stems. For each stoichiometric trait, a large proportion $(>44.9 \%)$ of total variations remained unexplained (Table 2).

\section{$\mathrm{N} v$ s. P scaling within leaves, stems and roots}

$\mathrm{N}$ and $\mathrm{P}$ were highly correlated within leaves, stems, and fine roots (all $P<0.001$; Fig. 3). In the three plant organs, the values of the allometric exponent $(a)$ were 0.78 , 0.71 and 0.87 for leaves, stems and roots, respectively (Table 5).

PGFs had a significant influence on allometric exponent of $\mathrm{N} v s . \mathrm{P}$ in the leaves, stem, and roots. In the leaves, the allometric exponent was remarkably different among herbs, shrubs and trees $(P<0.001$ for herbs $v s$. shrubs, herbs $v s$. trees and shrubs $v s$. trees; Fig. 3a). In the stems and roots, herbs and shrubs had a similar scaling relationship $(P=0.27$ and 0.29 in the likelihood ratio test for stems and fine roots, respectively), but differed compared to trees $(P<0.001 ;$ Fig. 3b, c). The intercepts $(b)$ of the scaling of $\mathrm{N}$ and $\mathrm{P}$ in leaves, stems and roots did not show significant difference among herbs, shrubs and trees (Table 5).

\section{$\mathrm{N} v$ s. P scaling along the environmental gradient}

In general, the stoichiometric scaling relationships in leaves, stems and roots did not show significant changes along the environmental gradient. The allometric exponents of the leaves for three PGFs showed no significant
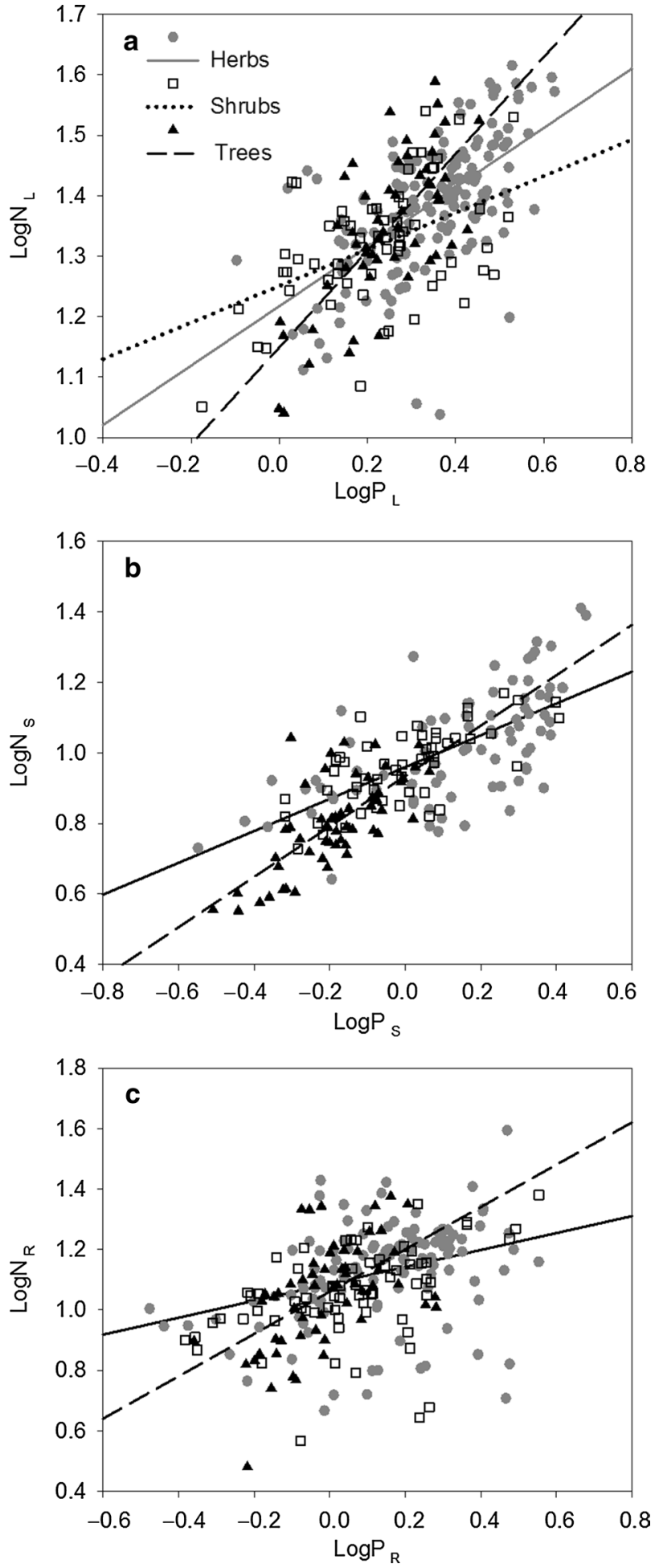

Fig. 3 Scaling of $\mathrm{N}$ as a function of $\mathrm{P}$ within leaves, stems and fine roots of the three plant growth forms. All lines are significant RMA regressions (likelihood ratio tests, $P<0.05$ ). In a, the regression slopes differ significantly among the three plant growth forms; thus, all the three regression lines are shown, for herbs (gray line), shrubs (dotted line) and trees (dash line). In $\mathbf{b}$ and $\mathbf{c}$, the regression slopes were not significantly different between herbs and shrubs; thus, herbs and shrubs are presented with a common regression line (black line), while that of trees (dash line) is presented separately 
difference at different altitudes (likelihood ratio tests, $P>0.05$; Fig. $4 \mathrm{a}, \mathrm{b}, \mathrm{c})$. The allometric exponents of the stems showed no significant changes (Fig. 4e, f), except that herbs had a higher allometric exponent in the low altitude zone (Fig. 4d). The allometric exponent of the roots for herbs in the middle altitude zone differed from that in
Herbs
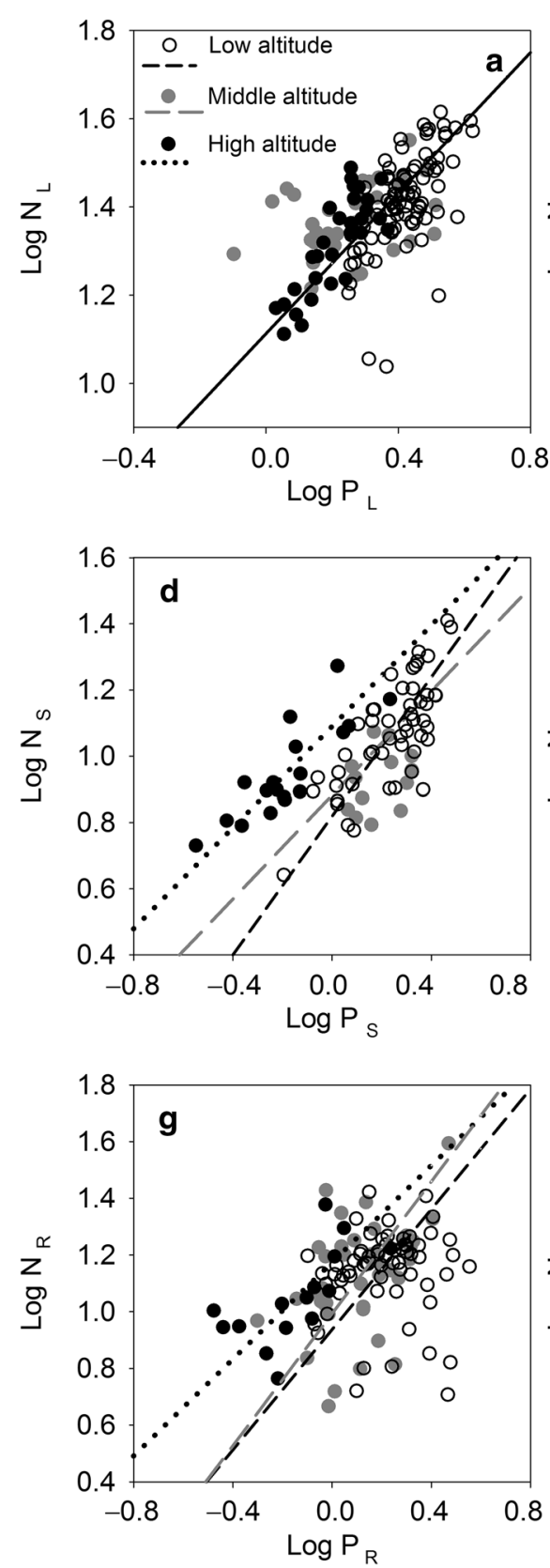

Shrubs
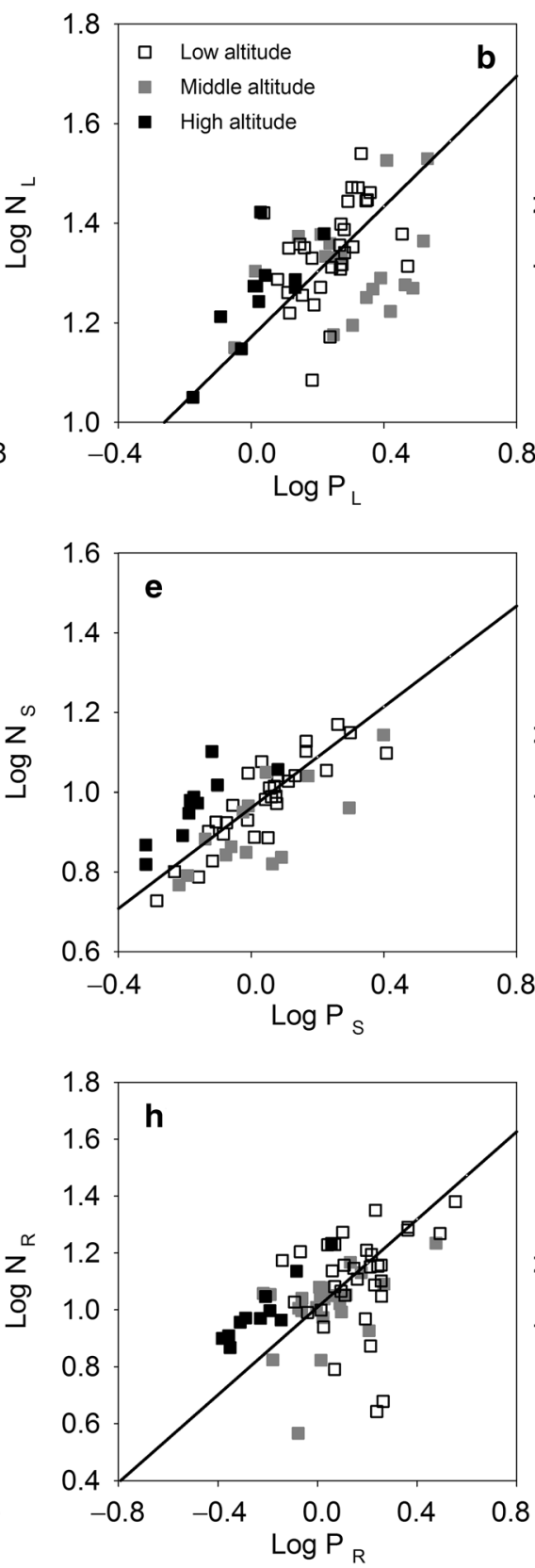

Trees
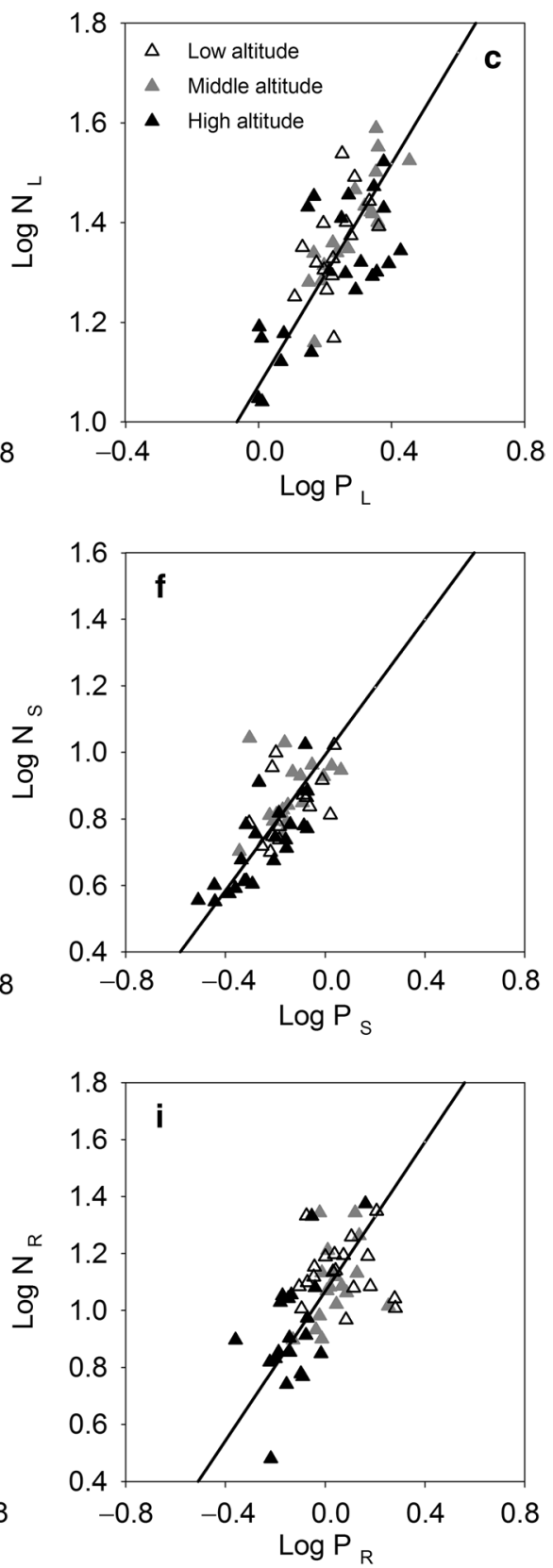

Fig. 4 Scaling of $\mathrm{N}$ as a function of $\mathrm{P}$ within leaves, stems and fine roots along the environmental gradient on Changbai Mountain, northeastern China. For plant growth forms: circles, squares and triangles represent herbs, shrubs and trees, respectively. For habitats: white, gray and black represented low, middle and high altitude, respectively. All lines are significant RMA regressions (likelihood ratio tests, $P<0.05)$. A single line indicates no significant difference in scaling slope at different altitudes; thus, the common regression line (black line) of the three altitude zones is shown. However, the slope was significantly higher at low altitude than middle and high altitude in $\mathbf{d}$; thus, the regression line of low altitude (dash line), and the regression line of middle (gray dash line) and high altitude (dotted line) are shown. In $\mathbf{g}$, the slope was found to be higher in the low and middle altitude zone than the high altitude zone; thus, all regression lines of the three altitude zones are shown 
the high altitude zone (Fig. 4g), whereas no significant changes were found for shrubs and trees along the environmental gradient (Fig. 4h, i).

\section{Discussion}

\section{Environmental factors and plant growth form influenced the altitudinal patterns of $\mathrm{N}, \mathrm{P}$ concentrations and $\mathrm{N}: \mathrm{P}$ ratio}

Our results showed that the $\mathrm{N}$ and $\mathrm{P}$ concentrations decreased, while N:P ratios increased with elevation for all three plant organs (Fig. 2). The changes of leaf nutrient were consistent with previous studies. Some studies on tropical, and subtropical mountains, and subarctic tundra found that leaf $\mathrm{N}$ and $\mathrm{P}$ declined with altitude (Köhler et al. 2006; Macek et al. 2009; Soethe et al. 2008; Sundqvist et al. 2011). By contrast, other studies also showed that the $\mathrm{N}$ and $\mathrm{P}$ of leaves first increased and then decreased with increasing elevation on Mountain Gongga, China (Shi et al. 2012) and in the Peruvian Andes (Fisher et al. 2013). Meanwhile, Garkoti (2012) indicated that root $\mathrm{N}$ and $\mathrm{P}$ declined with elevation in the central Himalayas.

The patterns of $\mathrm{N}$ and $\mathrm{P}$ concentrations reflected the variation of climate, soil nutrient and plant growth form along altitudinal gradient. The relative effects of climate, soil and plant growth form on stoichiometric traits of plant organs were different. Through the strong interactive effects, climate and soil intensively influenced $\mathrm{N}$ and $\mathrm{P}$ concentrations in leaves and fine roots (Table 2). By contrast, the total effect of plant growth form was relative important for $\mathrm{N}$ and $\mathrm{P}$ concentrations in stems (Table 2). Previous studies demonstrated that leaf $\mathrm{N}$ and $P$ variation reflected environmental conditions more than plant intrinsic characteristics, such as genotype (Ågren and Weih 2012) and taxonomy (Zhang et al. 2012). Although root nutrient concentrations were tightly associated with root diameter (Gordon and Jackson 2000), hierarchical branching and architecture (Iversen 2014; Li et al. 2010), they were also responsive indicators of soil nutrient availability (Burton et al. 2000; Holdaway et al. 2011) and climate at global and regional scale (Chen et al. 2013; Yuan et al. 2011). By contrast, stem which responsible for supporting and nutrient and water transport differed significantly in its construction costs among plant growth forms. For example, stems with high tissue density require greater construction costs, but have slower growth rate and lower nutrient concentrations (Fortunel et al. 2012; Li et al. 2010). Therefore, the relative importance of environment and plant growth form was correlated to organ functioning and metabolic activity. Organs with higher metabolic activity, such as leaf and fine root, reflect more environmental variation, whereas organs with slower metabolic activity reflect more instinct characteristics of plants.

\section{Consistent responses to environmental variations of leaves, stems and roots}

In this study, leaves, stems, and roots showed consistent responses of nutrient concentrations to environmental gradient, which could be rooted in the interdependence of plant nutrient acquisition. The leaf, stem and root were strongly linked in view of water, nutrient and metabolite storage, and transport (Fortunel et al. 2012; Gordon and Jackson 2000; Marschner et al. 1996). Leaf functioning depends on the water and nutrients absorbed by the roots, while root growth, in turn, depends on the carbohydrates produced by the leaves. Despite of the uncertainty and inconsistency of the trade-offs among leaf- and root-trait syndromes, existing evidence indicated that there can be certain positive correlations of $\mathrm{N}$ and $\mathrm{P}$ concentrations among the leaf, stem and root (Geng et al. 2014; Kerkhoff et al. 2006; Liu et al. 2010; Yang et al. 2014). This positive correlation, in some extent, reflected a coordination of leaf, stem and root tissue resource capture strategies. Previous studies found a "slow-return" strategy of leaves (Wright et al. 2004) to make plant more resistant to temperature stress and nutrient limitation. Meanwhile, a similar strategy has also been reported in root systems (Burton et al. 2000; Pregitzer et al. 2000). It suggested that plant might coordinately decline the metabolic rates and nutrient content of above and below plant organs to maximize plant fitness under stressful environments.

\section{Conservatism of $\mathbf{N}$ and $\mathbf{P}$ scaling relationship in leaves, stems and roots}

The scaling relationship of $\mathrm{N}$ and $\mathrm{P}$ showed different response to environmental variation among different organs. The leaves of three plant growth forms exhibited invariant scaling slopes, whereas the scaling slopes of the stems and roots for herbaceous species changed with increased elevation (Fig. 4). This result implied that the N to $\mathrm{P}$ relationship was more stable in the leaf than it in the stem and root. It was consistent with previous study that a uniform scaling relationship of leaf $\mathrm{N}$ to $\mathrm{P}$ was found based on 2,500 plant species across dramatic environment gradients (Reich et al. 2010). A recent study provided evidence 
that leaves and diaspores showed higher conservatism of $\mathrm{N}$ and $\mathrm{P}$ stoichiometry than stems and belowground organs (Minden and Kleyer 2014). Therefore, the conservatism of $\mathrm{N}$ and $\mathrm{P}$ scaling relationship might different among different plant organs.

The variation of scaling slopes was only detected in herbaceous species, whereas woody species showed an invariant scaling relationship of $\mathrm{N}$ and $\mathrm{P}$ in leaves, stems and roots (Fig. 4). Our results demonstrated that the scaling relationship of $\mathrm{N}$ and $\mathrm{P}$ was significantly different between herbaceous and woody species in response to environmental variations. Compared to woody species, herbaceous species were characterized by quick growth, high leaf nutrient contents, and fast life histories (Adler et al. 2014; Grime 1977). In our study, herbaceous species exhibited a flatter scaling slope in the stems and roots with increased elevation, which implied a faster declination of $\mathrm{P}$ than $\mathrm{N}$. In order to survive in low-nutrient habits, herbaceous species might ensure the nutrient supply of the leaves at the expense of declining $\mathrm{P}$ allocation to the stems and roots. In parallel, the invariant scaling slopes showed that woody species were less responsive to environmental constraints and had higher conservatism in nutrient allocation than herbaceous species. Thus, the conservatism of scaling of $\mathrm{N}$ and $\mathrm{P}$ might be different among plant growth forms, which were distinct in different nutrient strategy.

\section{Conclusions}

This study investigated the scaling relationship of $\mathrm{N}$ and $\mathrm{P}$ in different plant organs and their response to an altitudinal gradient. The $\mathrm{N}$ and $\mathrm{P}$ concentrations of the leaves, stems and fine roots showed a consistent response to the environmental gradient; specifically, for all three organs, $\mathrm{N}$ and $\mathrm{P}$ concentrations decreased while $\mathrm{N}: \mathrm{P}$ ratios increased with elevation. The allometric scaling relationships of $\mathrm{N}$ and $\mathrm{P}$ were found in all three organs. Additionally, the scaling slopes varied in the stems and roots of herbaceous species, whereas woody species showed an invariant scaling slope of $\mathrm{N}$ and $\mathrm{P}$ along the altitudinal gradient.

Acknowledgments This work was supported by the Major Program of the National Natural Science Foundation of China [No. 31290221], and the Program for "Kezhen" Distinguished Talents in Institute of Geographic Sciences and Natural Resources Research, CAS. We thank teachers and students of Beihua University of China for field sampling assistance and the staff of Key Laboratory of Ecosystem Network Observation and Modelling of IGSNRR, CAS for laboratory analysis.

\section{Appendix}

See Table 3, 4, 5 .

Table 3 Model summary for the stepwise multiple regression of stoichiometric traits on two climatic variables (MAP and MAT)

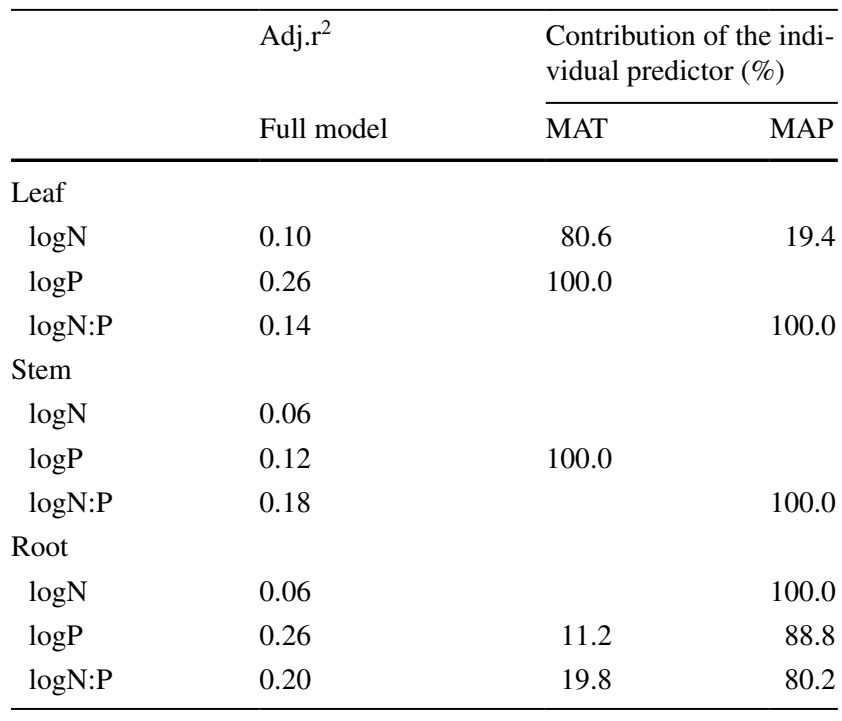

MAT mean annual temperature, MAP mean annual precipitation

Table 4 Model summary for the stepwise multiple regression of stoichiometric traits on four soil variables (STN, STP, SAN and SAP)

\begin{tabular}{clllll}
\hline & Adj. $\mathrm{r}^{2}$ & \multicolumn{3}{l}{$\begin{array}{l}\text { Contribution of the individual predic- } \\
\text { tor }(\%)\end{array}$} \\
\cline { 3 - 6 } & Full model & STN & STP & SAN & SAP \\
\hline Leaf & & & & & \\
$\log \mathrm{N}$ & 0.17 & 23.6 & 64.6 & & 11.8 \\
$\log \mathrm{P}$ & 0.25 & & 49.6 & 50.4 & \\
$\log \mathrm{N}: \mathrm{P}$ & 0.27 & & 39.8 & 4.2 & 56 \\
Stem & & & & & \\
$\log \mathrm{N}$ & 0.19 & & 55.7 & & 44.3 \\
$\log \mathrm{P}$ & 0.18 & 15.2 & 84.8 & & \\
$\log \mathrm{N}: \mathrm{P}$ & 0.34 & 27.4 & 32.2 & 17.6 & 22.8 \\
Root & & & & & \\
$\log \mathrm{N}$ & 0.15 & & 100 & & \\
$\log \mathrm{P}$ & 0.27 & & 78.6 & & 21.4 \\
$\log \mathrm{N}: \mathrm{P}$ & 0.16 & & & & 100 \\
\hline
\end{tabular}

STN soil total nitrogen, STP soil total phosphorus, $S A N$ soil available nitrogen, $S A P$ soil available phosphorus 
Table 5 Summary of reduced major axis (RMA) regression results for leaves, stems and roots

\begin{tabular}{lrllllll}
\hline \multicolumn{2}{c}{$\mathrm{n}$} & $\mathrm{a}_{\mathrm{RMA}}$ & $95 \% \mathrm{CI}$ & $\mathrm{b}_{\mathrm{RMA}}$ & $95 \% \mathrm{CI}$ & $\mathrm{r}^{2}$ & $P$ \\
\hline $\begin{array}{l}\text { Regression N } \\
\text { Leaves }\end{array}$ & & & & & & & \\
All & 269 & 0.78 & $0.71-0.85$ & 1.13 & $1.11-1.15$ & 0.39 & $4.07 \mathrm{E}-30$ \\
Herbs & 153 & 0.80 & $0.7-0.9$ & 1.11 & $1.08-1.14$ & 0.38 & $2.29 \mathrm{E}-17$ \\
Shrubs & 61 & 0.66 & $0.52-0.82$ & 1.17 & $1.13-1.2$ & 0.21 & $1.79 \mathrm{E}-04$ \\
Trees & 55 & 1.11 & $0.92-1.35$ & 1.07 & $1.02-1.12$ & 0.52 & $6.85 \mathrm{E}-10$ \\
Stems & & & & & & & \\
All & 188 & 0.71 & $0.65-0.78$ & 0.94 & $0.94-0.94$ & 0.59 & $1.15 \mathrm{E}-37$ \\
Herbs & 82 & 0.69 & $0.59-0.82$ & 0.93 & $0.91-0.94$ & 0.42 & $4.03 \mathrm{E}-11$ \\
Shrubs & 53 & 0.63 & $0.52-0.77$ & 0.96 & $0.96-0.96$ & 0.50 & $3.37 \mathrm{E}-09$ \\
Trees & 53 & 1.02 & $0.83-1.24$ & 0.99 & $0.96-1.03$ & 0.49 & $5.18 \mathrm{E}-09$ \\
Roots & & & & & & & \\
All & 247 & 0.87 & $0.77-0.97$ & 1.02 & $1.01-1.03$ & 0.18 & $4.92 \mathrm{E}-12$ \\
Herbs & 122 & 0.84 & $0.71-1$ & 1.01 & $0.99-1.03$ & 0.11 & $1.89 \mathrm{E}-04$ \\
Shrubs & 68 & 0.77 & $0.62-0.96$ & 1.01 & $1-1.02$ & 0.19 & $2.43 \mathrm{E}-04$ \\
Trees & 57 & 1.31 & $1.04-1.64$ & 1.07 & $1.06-1.07$ & 0.29 & $1.87 \mathrm{E}-05$ \\
\hline
\end{tabular}

$n$ represent the number of site-species

\section{References}

Adler PB, Salguero-Gómez R, Compagnoni A, Hsu JS, Ray-Mukherjee J, Mbeau-Ache C, Franco M (2014) Functional traits explain variation in plant life history strategies. Proc Natl Acad Sci USA 111:740-745. doi:10.1073/pnas.1315179111

Ågren GI (2004) The C: N: P stoichiometry of autotrophs-theory and observations. Ecol Lett 7:185-191. doi:10.1111/j.1461-0248.2004.00567.x

Ågren GI (2008) Stoichiometry and nutrition of plant growth in natural communities. Annu Rev Ecol, Evol Syst 39:153-170. doi:10.1146/annurev.ecolsys.39.110707.173515

Ågren GI, Weih M (2012) Plant stoichiometry at different scales: element concentration patterns reflect environment more than genotype. New Phytol 194:944-952. doi:10.1111/j.1469-8137.2012.04114.x

Brown JH, Gillooly JF, Allen AP, Savage VM, West GB (2004) Toward a metabolic theory of ecology. Ecology 85:1771-1789. doi:10.1890/03-9000

Burton AJ, Pregitzer KS, Hendrick RL (2000) Relationships between fine root dynamics and nitrogen availability in Michigan northern hardwood forests. Oecologia 125:389-399. doi:10.1007/ s004420000455

Chapin FS III, Vitousek PM, Vancleve K (1986) The nature of nutrient limitation in plant communities. Am Nat 127:48-58

Chen WL, Zeng H, Eissenstat DM, Guo DL (2013) Variation of first-order root traits across climatic gradients and evolutionary trends in geological time. Glob Ecol Biogeogr 22:846-856. doi:10.1111/geb.12048

Chen YH, Han WX, Tang LY, Tang ZY, Fang JY (2011) Leaf nitrogen and phosphorus concentrations of woody plants differ in responses to climate, soil and plant growth form. Ecography 36:178-184. doi:10.1111/j.1600-0587.2011.06833.x

Dijkstra FA, Pendall E, Morgan JA et al (2012) Climate change alters stoichiometry of phosphorus and nitrogen in a semiarid grassland. New Phytol 196:807-815. doi:10.1111/j.1469-8137.2012.04349.x

Elser JJ, Bracken ME, Cleland EE et al (2007) Global analysis of nitrogen and phosphorus limitation of primary producers in freshwater, marine and terrestrial ecosystems. Ecol Lett 10:1135-1142. doi:10.1111/j.1461-0248.2007.01113.x
Elser JJ, Fagan WF, Kerkhoff AJ, Swenson NG, Enquist BJ (2010) Biological stoichiometry of plant production: metabolism, scaling and ecological response to global change. New Phytol 186:593-608. doi:10.1111/j.1469-8137.2010.03214.x

Fisher JB, Malhi Y, Torres IC et al (2013) Nutrient limitation in rainforests and cloud forests along a 3,000-m elevation gradient in the Peruvian Andes. Oecologia 172:889-902. doi:10.1007/ s00442-012-2522-6

Fortunel C, Fine PV, Baraloto C (2012) Leaf, stem and root tissue strategies across 758 Neotropical tree species. Funct Ecol 26:1153-1161. doi:10.1111/j.1365-2435.2012.02020.x

Güsewell S (2004) N: P ratios in terrestrial plants: variation and functional significance New Phytol 164:243-266 doi:10.1111/j.1469-8137.2004.01192.x

Garkoti SC (2012) Dynamics of fine root N. Pand K in high elevation forests of central Himalaya Forestry Studies in China 14:145151. doi:10.1007/s11632-012-0203-5

Garten CT (1976) Correlations between concentrations of elements in plants. Nature 261:686-688. doi:10.1038/261686a0

Geng Y, Wang L, Jin DM, Liu HY, He JS (2014) Alpine climate alters the relationships between leaf and root morphological traits but not chemical traits. Oecologia 175:445-455. doi:10.1007/ s00442-014-2919-5

Gordon WS, Jackson RB (2000) Nutrient concentrations in fine roots. Ecology 81:275-280. doi:10.1890/0012-9658(2000)081[0275:NCI FR]2.0.CO;2

Grime JP (1977) Evidence for the existence of three primary strategies in plants and its relevance to ecological and evolutionary theory. Am Nat 111:1169-1194

Han WX, Fang JY, Guo DL, Zhang Y (2005) Leaf nitrogen and phosphorus stoichiometry across 753 terrestrial plant species in China. New Phytol 168:377-385. doi:10.1111/j.1469-8137.2005.01530.x

Han WX, Fang JY, Reich PB, Ian Woodward F, Wang ZH (2011) Biogeography and variability of eleven mineral elements in plant leaves across gradients of climate, soil and plant functional type in China. Ecol Lett 14:788-796

Hao Z, Kuang Y, Kang M (2014) Untangling the influence of phylogeny, soil and climate on leaf element concentrations in a biodiversity hotspot. Funct Ecol 29:165-176. doi:10.1111/1365-2435.12344 
Heberling JM, Fridley JD (2012) Biogeographic constraints on the world-wide leaf economics spectrum. Glob Ecol Biogeogr 21:1137-1146. doi:10.1111/j.1466-8238.2012.00761.x

Heikkinen RK, Luoto M, Kuussaari M, Pöyry J (2005) New insights into butterfly-environment relationships using partitioning methods. P R Soc B 272:2203-2210

Holdaway RJ, Richardson SJ, Dickie IA, Peltzer DA, Coomes DA (2011) Species- and community- level patterns in fine root traits along a 120,000-year soil chronosequence in temperate rain forest. J Ecol 99:954-963

Iversen CM (2014) Using root form to improve our understanding of root function. New Phytol 203:707-709. doi:10.1111/ nph. 12902

Köhler L, Gieger T, Leuschner C (2006) Altitudinal change in soil and foliar nutrient concentrations and in microclimate across the tree line on the subtropical island mountain Mt. Teide (Canary Islands). Flora 201:202-214 doi:10.1016/j.flora.2005.07.003

Kerkhoff AJ, Enquist BJ, Elser JJ, Fagan WF (2005) Plant allometry, stoichiometry and the temperature dependence of primary productivity. Glob Ecol Biogeogr 14:585-598. doi:10.1111/j.1466-822X.2005.00187.x

Kerkhoff AJ, Fagan WF, Elser JJ, Enquist BJ (2006) Phylogenetic and growth form variation in the scaling of nitrogen and phosphorus in the seed plants. Am Nat 168:E103-E122. doi:10.1086/507879

Legendre P, Legendre L (1998) Numerical ecology, 2nd English edition edn. Elsevier Science BV, Amsterdam

Li A, Guo DL, Wang ZQ, Liu HY (2010) Nitrogen and phosphorus allocation in leaves, twigs, and fine roots across 49 temperate, subtropical and tropical tree species: a hierarchical pattern. Funct Ecol 24:224-232

Liu GF, Freschet GT, Pan X, Cornelissen JHC, Li Y, Dong M (2010) Coordinated variation in leaf and root traits across multiple spatial scales in Chinese semi-arid and arid ecosystems. New Phytol 188:543-553. doi:10.1111/j.1469-8137.2010.03388.x

Macek P, Macková J, de Bello F (2009) Morphological and ecophysiological traits shaping altitudinal distribution of three Polylepis treeline species in the dry tropical Andes. Acta Oecol 35:778785. doi:10.1016/j.actao.2009.08.013

Marschner H, Kirkby E, Cakmak I (1996) Effect of mineral nutritional status on shoot-root partitioning of photoassimilates and cycling of mineral nutrients. J Exp Bot 47:1255-1263. doi:10.1093/jxb/47.Special_Issue.1255

Minden V, Kleyer M (2014) Internal and external regulation of plant organ stoichiometry. Plant Biol 16:897-907. doi:10.1111/ plb. 12155

Pregitzer KS, King JS, Burton AJ, Brown SE (2000) Responses of tree fine roots to temperature. New Phytol 147:105-115. doi:10.1046/j.1469-8137.2000.00689.x

Price CA, Weitz JS, Savage VM et al (2012) Testing the metabolic theory of ecology. Ecol Lett 15:1465-1474. doi:10.1111/j.1461-0248.2012.01860.x

R Core Team (2014) R: A Language and Environment for Statistical Computing. R Foundation for Statistical Computing, Vienna. http://www.R-project.org

Reich PB, Oleksyn J (2004) Global patterns of plant leaf N and P in relation to temperature and latitude. Proc Natl Acad Sci USA 101:11001-11006. doi:10.1073/pnas.0403588101

Reich PB, Oleksyn J, Wright IJ, Niklas KJ, Hedin L, Elser JJ (2010) Evidence of a general 2/3-power law of scaling leaf nitrogen to phosphorus among major plant groups and biomes. P R Soc B 277:877-883. doi:10.1098/rspb.2009.1818
Shao G, Shugart HH, Zhao G, Zhao S, Wang S, Schaller J (1996) Forest cover types derived from Landsat Thematic Mapper imagery for Changbai Mountain area of China. Can J For Res 26:206216. doi:10.1139/x26-024

Shi WQ, Wang GA, Han WX (2012) Altitudinal variation in leaf nitrogen concentration on the eastern slope of Mount Gongga on the Tibetan Plateau. China. PloS one 7:e44628. doi:10.1371/ journal.pone.0044628

Soethe N, Lehmann J, Engels C (2008) Nutrient availability at different altitudes in a tropical montane forest in Ecuador. J Trop Ecol 24:397. doi:10.1017/S026646740800504X

Sokal RR, Rohlf FJ (1981) Biometry: the principles and practice of statistics in biological research. W.H. Freeman and Company, New York

Stock WD, Verboom GA (2012) Phylogenetic ecology of foliar $\mathrm{N}$ and $\mathrm{P}$ concentrations and $\mathrm{N}$ : $\mathrm{P}$ ratios across mediterranean-type ecosystems. Glob Ecol Biogeogr 21:1147-1156. doi:10.1111/j.1466-8238.2011.00752.x

Sundqvist MK, Giesler R, Wardle DA (2011) Within-and across-species responses of plant traits and litter decomposition to elevation across contrasting vegetation types in subarctic tundra. PloS One 6:e27056. doi:10.1371/journal.pone.0027056

Vitousek PM, Porder S, Houlton BZ, Chadwick OA (2010) Terrestrial phosphorus limitation: mechanisms, implications, and nitrogen-phosphorus interactions. Ecol Appl 20:5-15. doi:10.1890/08-0127.1

Westoby M, Falster DS, Moles AT, Vesk PA, Wright IJ (2002) Plant ecological strategies: some leading dimensions of variation between species. Annu Rev Ecol, Evol Syst. 125-159 doi:10.1146/annurev.ecolsys.33.010802.150452

Wright IJ, Reich PB, Westoby M et al (2004) The worldwide leaf economics spectrum. Nature 428:821-827. doi:10.1038/ nature 02403

Xiang S, Reich PB, Sun SC, Atkin OK (2013) Contrasting leaf trait scaling relationships in tropical and temperate wet forest species. Funct Ecol 27:522-534. doi:10.1111/1365-2435.12047

Yang X, Tang ZY, Ji CJ et al (2014) Scaling of nitrogen and phosphorus across plant organs in shrubland biomes across Northern China. Sci Rep 4:5448. doi:10.1038/srep05448

Yuan ZY, Chen HY, Reich PB (2011) Global-scale latitudinal patterns of plant fine-root nitrogen and phosphorus. Nat Commun 2:344. doi: $10.1038 /$ ncomms 1346

Zhang M, Zhang XK, Liang WJ, Jiang Y, Dai GH, Wang XG, Han SJ (2011) Distribution of soil organic carbon fractions along the altitudinal gradient in Changbai Mountain. China Pedosphere 21:615-620. doi:10.1016/S1002-0160(11)60163-X

Zhang SB, Zhang JL, Slik J, Cao KF (2012) Leaf element concentrations of terrestrial plants across China are influenced by taxonomy and the environment. Glob Ecol Biogeogr 21:809-818. doi:10.1111/j.1466-8238.2011.00729.x

Zhao N, He NP, Wang QF, Zhang XY, Wang RL, Xu ZW, Yu GR (2014) The altitudinal patterns of leaf C: N: P stoichiometry are regulated by plant growth form, climate and soil on Changbai Mountain, China. PloS one 9:e95196. doi:10.1371/journal. pone.0095196

Zhu B, Wang XP, Fang JY, Piao SL, Shen HH, Zhao SQ, Peng CH (2010) Altitudinal changes in carbon storage of temperate forests on Mt Changbai, Northeast China. J Plant Res 123:439-452. doi:10.1007/s10265-009-0301-1 